Table 1. The dynamics of the disease activity during treatment with TOFA

\begin{tabular}{|c|c|c|c|c|}
\hline Parameters & Weeks & $\begin{array}{l}\text { All patients } \\
(\mathrm{n}=138)\end{array}$ & $\begin{array}{l}\text { Had prior biologic use } \\
\text { history (group 1) }(n=51)\end{array}$ & $\begin{array}{l}\text { Biologic naive } \\
\text { (group 2) }(n=87)\end{array}$ \\
\hline \multirow[t]{4}{*}{ DAS28 } & baseline & $5,5(4,6-6,2)$ & $5,1(4,5-5,9)$ & $5,7(4,8-6,5) \$$ \\
\hline & week 12 & $4,2(3,1-4,8)^{\star}$ & $3,9(2,8-4,8)^{*}$ & $4,4(3,7-4,8)^{\star}$ \\
\hline & week 24 & $3,4(2,7-4,4)^{\star}$ & $3,5(2,4-4,3)^{*}$ & $3,4(2,8-4,5)^{*}$ \\
\hline & week 48 & $3,3(2,5-4,4)^{\star}$ & $3,2(2,4-4,2)^{\star}$ & $3,4(2,7-4,4)^{\star}$ \\
\hline \multirow{4}{*}{ SDAI } & baseline & $30,5(21,4-42,9)$ & $28,6(18,1-36,6)$ & $33,1(22,6-45,9)$ \\
\hline & week 12 & $14,5(7,1-23,3)^{\star}$ & $13,1(5,1-19,1)^{\star}$ & $16,3(9,3-25,6)^{*}$ \\
\hline & week 24 & $10,5(5,1-19,0)^{*}$ & $11,0(5,5-17,6)^{\star}$ & $9,1(4,7-20,4)^{\star}$ \\
\hline & week 48 & $10,3(4,9-17,7)^{*}$ & $10,2(3,4-15,8)^{*}$ & $10,9(6,2-18,1)^{\star}$ \\
\hline \multirow[t]{4}{*}{ CDAI } & baseline & $28,2(20,0-37,1)$ & $25,7(17,0-33,7)$ & $30,0(21,5-40,5)$ \\
\hline & week 12 & $14,9(8,0-22,5)^{\star}$ & $13,0(6,8-18,7)^{\star}$ & $16,6(9,0-24,0)^{*}$ \\
\hline & week 24 & $10,0(5,0-18,0)^{*}$ & $11,0(4,7-16,0)^{\star}$ & $9,3(5,0-18,0)^{\star}$ \\
\hline & week 48 & $10,1(5,8-17,0)^{\star}$ & $10,4(4,0-16,0)^{\star}$ & $10,0(6,0-17,0)^{\star}$ \\
\hline \multirow[t]{4}{*}{ CRP, mg/l } & baseline & $15,6(6,5-38,0)$ & $15,6(6,0-38,1)$ & $15,4(6,9-36,7)$ \\
\hline & week 12 & $5,5(1,7-12,1)^{\star}$ & $6,4(2,7-10,4)^{\star}$ & $5,2(1,3-12,8)^{\star}$ \\
\hline & week 24 & $4,5(1,0-10,0)^{\star}$ & $5,0(0,8-9,8)^{*}$ & $4,2(1,0-10,0)^{*}$ \\
\hline & week 48 & $4,0(0,7-9,0)^{\star}$ & $2,9(0,6-9,6)^{\star}$ & $4,0(0,8-8,9)^{\star}$ \\
\hline \multirow[t]{4}{*}{$\mathrm{ESR}, \mathrm{mm} / \mathrm{h}$} & baseline & $32,0(23,0-48,0)$ & $29,0(16,0-37,0)$ & $32,0(23,0-49,0) \$$ \\
\hline & week 12 & $21,0(17,0-33,0)^{\star}$ & $20,0(12,0-33,0)$ & $21,0(17,0-33,0)^{*}$ \\
\hline & week 24 & $21,0(12,0-31,0)^{\star}$ & $13,0(9,0-28,0)$ & $21,0(12,0-31,0)^{\star}$ \\
\hline & week 48 & $16,0(10,0-27,0)^{*}$ & $16,0(7,0-30,0)^{*}$ & $16,0(10,0-27,0)^{\star}$ \\
\hline
\end{tabular}

${ }^{*} p<0.05$ from baseline; $\$ p<0.05$ between the groups 1 and 2

Patients of the second group had a higher disease activity and ESR before therapy. The use of TOFA was accompanied by a decrease in the disease activity and the level of acute phase reactants (CRP and ESR) in both groups of patients. By week 48 of treatment, no significant difference between the groups according to the disease activity was detected.

In the first and the second group of pts on the 48-th week of therapy remission/ low disease activity was achieved on DAS 28 in $51 \%$ and $43 \%(p=0.57)$, high disease activity on DAS 28 in $12 \%$ and $8 \%(p=0.48)$

Conclusion: An analysis of the data from the Russian national register of patients with RA demonstrated similar efficacy of TOFA among patients who received and did not receive previous biological therapy.

Disclosure of Interests: Evgeny Nasonov Speakers bureau: Lilly, AbbVie, Pfizer, Biocad, R-Pharm, Anastasia Avdeeva: None declared, Anna Misiyuk: None declared, Azamat Satybaldyev: None declared, Valentina Sorotskaya: None declared, Oxana Fomina: None declared, Aida Babaeva: None declared, N Lapkina: None declared, Alexander Lila: None declared DOI: 10.1136/annrheumdis-2020-eular.3052

\section{AB0329 1 PHYSICIANS' PRE-LAUNCH AWARENESS AND CONCERNS WITH PIPELINE JANUS KINASE INHIBITORS (JAKIS) VERSUS TOFACITINIB AND BARICITINIB IN RHEUMATOID ARTHRITIS IN THE UNITED STATES AND EUROPE}

\section{Baldock ${ }^{1}$, G. Giannakopoulou ${ }^{1} .{ }^{1}$ Ipsos MORI, London, United Kingdom}

Background: Clinical data regarding use of tofacitinib and baricitinib in rheumatoid arthritis patients have recently posed safety concerns, with regulatory bodies suggesting limiting use of higher dosages. Investigating physicians' awareness and views of each of these products leading up to their launch, as well as the physicians' patient characteristics, may provide evidence of how pipeline JAKis could be received in the treatment landscape once approved. Objectives: The objective of the study was to investigate awareness and anticipated concerns of upcoming versus already launched JAKis among a sample of treating rheumatologists in the US and EU5 countries, and assess potential correlation between sampled physicians' views on JAKis and their managed patient characteristics.

Methods: A multi-country, multi-center online medical chart review study of patients with RA was conducted across 2011 - 2019 among rheumatologists in hospitals and private practices to collect de-identified data on a sample of patients who were recently treated with a biologic/JAKi in the USA \& EU5 (UK, France, Italy, Spain, Germany). Physicians were screened for duration of practice (3-30 years) and patient volume ( $\geq 2$ RA biologic/JAKi patients per week) and recruited from a large, geographically representative access panel. Patient charts were recorded for the next 5 eligible patients seen during the screening period. Respondents abstracted patient demographics and personal awareness and concerns for drugs in development. Sites waived local ethics review owing to collection of retrospective de-identified data. Data were analyzed using descriptive statistics.

Results: In Q1 $19,56.2 \%$ and $56.2 \%$ of sampled US physicians were aware of upadacitinib (upa) and filgotinib (filgo), respectively ${ }^{1}$. Prior to US launch, tofacitinib (tofa) and baricitinib (bari) achieved respective awarenesses of 89.9\% (Q4 11, $\mathrm{n}=109)^{2}$ and 85.2\% (Q2 17, $\left.\mathrm{n}=101\right)^{3}$. Among 262 sampled EU5 rheumatologists, pre-launch awareness in of upa and filgo in Q1 19 was $46.2 \%$ and $45.8 \%{ }^{1}$, while for tofa and bari it was $46.2 \%$ and $45.8 \%$, respectively (Q2 $16, n=380)^{4}$. 'Poor safety profile' was cited as a common anticipated concern for upa and filgo, $9.9 \%$ of sampled physicians aware of upa $(n=121)$ and $7.5 \%$ of those aware of filgo $(n=120)^{1}$, with the respective scores for tofa and bari prior to their launch being $16.9 \%(n=296)$ and $14.5 \%(n=227)^{4}$. Sampled patient characteristics in each physician segment (upa concerned $n=449$ patients / non-concerned, $\mathrm{n}=155$ patients; filgo concerned, $\mathrm{n}=454$ patients /non-concerned, $\mathrm{n}=145$ patients) included: (a) age in years 54.6/51, $\mathrm{p}<0.01 ; 53.9 / 51.2$, $\mathrm{p}<0.05$ (b) retired employment status $31 \% / 20.6 \%, p<0.05 ; 29.5 \% / 20 \%, p<0.05$

Conclusion: In this sample, upa and filgo achieved lower awareness scores, compared to tofa and bari prior their launch. Sampled EU5 physicians were less concerned with upa and filgo's safety profiles, than for the other two JAKis before launch. Sampled physicians holding concerns with upa/filgo manage significantly older patients and a significantly higher number of retired patients. Further investigation using comparator cohort is warranted

References:

[1] Ipsos Global Rheumatoid Arthritis Therapy Monitor (Q1 2019, 262 sampled rheumatologists in the EU and 115 sampled rheumatologists in the US reporting on a sample of RA patients seen in their practice; data collected online).

[2] Ipsos Global Rheumatoid Arthritis Therapy Monitor (Q4 2011, 109 sampled rheumatologists in the US reporting on a sample of RA patients seen in their practice; data collected online).

[3] Ipsos Global Rheumatoid Arthritis Therapy Monitor (Q2 2017, 101 sampled rheumatologists in the US reporting on a sample of RA patients seen in their practice; data collected online)

[4] Ipsos Global Rheumatoid Arthritis Therapy Monitor (Q2 2016, 380 sampled rheumatologists in the EU reporting on a sample of RA patients seen in their practice; data collected online)

(C) Ipsos 2020, all rights reserved

Disclosure of Interests: None declared

DOI: 10.1136/annrheumdis-2020-eular.2194

\section{$\mathrm{AB} 0330$ HIGH REMISSION RATES IN RA - REAL LIFE DATA FROM BARITICINIB}

S. Bayat ${ }^{1}$, K. Tascilar ${ }^{1}$, V. Kaufmann ${ }^{1}$, A. Kleyer ${ }^{1}$, D. Simon ${ }^{1}$, J. Knitza ${ }^{1}$,

F. Hartmann', S. Adam ${ }^{1}$, A. Hueber ${ }^{2}$, G. Schett ${ }^{1}$. 'University Hospital Erlangen; Department of Internal Medicine ${ }^{3}$ - Rheumatology and Immunology, Friedrich-Alexander University (FAU) Erlangen-Nürnberg, Erlangen, Germany; ${ }^{2}$ Sozialstiftung Bamberg; Rheumatology, Bamberg, Germany

Background: Recent developments of targeted treatments such as targeted synthetic DMARDs (tsDMARDs) increase the chances of a sustained low disease activity (LDA) or remission state for patients suffering rheumatoid arthritis (RA). tsDMARDs such as baricitinib, an oral inhibitor of the Janus Kinases (JAK1/JAK2) was recently approved for the treatment of RA with an inadequate response to conventional (CDMARD) and biological (bDMARD) therapy. $(1,2)$.

Objectives: Aim of this study is to analyze the effect of baricitinb on disease activity (DAS28, LDA) in patients with RA in real life, to analyze drug persistance and associate these effects with various baseline characteristics.

Methods: All RA patients were seen in our outpatient clinic. If a patient was switched to a baricitinib due to medical reasons, these patients were included in our prospective, observational study which started in April 2017. Clinical scores (SJC/TJC 76/78), composite scores (DAS28), PROs (HAQ-DI; RAID; FACIT), safety parameters (not reported in this abstract) as well as laboratory biomarkers were collected at each visit every three months. Linear mixed effects models for repeated measurements were used to analyze the time course of disease activity, patient reported outcomes and laboratory results. We estimated the probabilities of continued baricitinib treatment and the probabilities of LDA and remission by DAS-28 as well as Boolean remission up to one year using survival analysis and explored their association with disease characteristics using multivariable Cox regression. All patients gave informed consent. The study is approved by the local ethics.

Results: 95 patients were included and 85 analyzed with available follow-up data until November 2019. Demographics are shown in table 1. Mean follow-up duration after starting baricitinib was 49.3 (28.9) weeks. 51 patients $(60 \%)$ were on monotherapy. Baricitinib survival $(95 \% \mathrm{Cl})$ was $82 \%(73 \%$ to $91 \%)$ at one year. Cumulative number (\%probability, $95 \% \mathrm{Cl}$ ) of patients that 
attained DAS-28 LDA at least once up to one year was 67 (92\%, 80\% to 97\%) and the number of patients attaining DAS-28 and Boolean remission were $31(50 \%, 34 \%$ to $61 \%)$ and $12(20 \%, 9 \%$ to $30 \%)$ respectively. Median time to DAS-28 LDA was 16 weeks (Figure 1). Cox regression analyses did not show any sufficiently precise association of remission or LDA with age, gender, seropositivity, disease duration, concomitant DMARD use and number of previous bDMARDs. Increasing number of previous bDMARDs was associated with poor baricitinib survival $(\mathrm{HR}=1.5,95 \% \mathrm{Cl} 1.1$ to 2.2$)$ while this association was not robust to adjustment for baseline disease activity. Favorable changes were observed in tender and swollen joint counts, pain-VAS, patient and physician disease assessment scores, RAID, FACIT and the acute phase response.

Conclusion: In this prospective observational study, we observed high rates of LDA and DAS-28 remission and significant improvements in disease activity and patient reported outcome measurements over time.

References:

[1] Keystone EC, Taylor PC, Drescher E, Schlichting DE, Beattie SD, Berclaz PY, et al. Safety and efficacy of baricitinib at 24 weeks in patients with rheumatoid arthritis who have had an inadequate response to methotrexate. Annals of the rheumatic diseases. 2015 Feb;74(2):333-40.

[2] Genovese MC, Kremer J, Zamani O, Ludivico C, Krogulec M, Xie L, et al. Baricitinib in Patients with Refractory Rheumatoid Arthritis. The New England journal of medicine. 2016 Mar 31;374(13):1243-52.
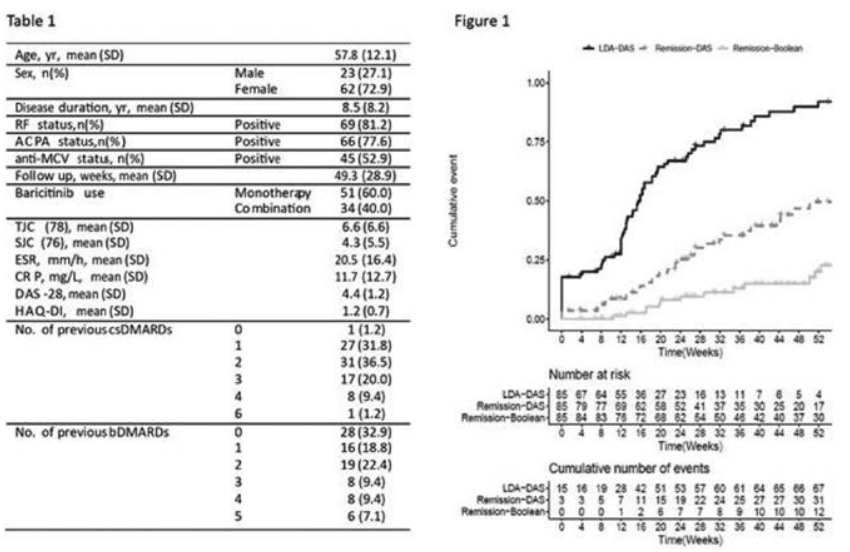

Figure 1. Cumulative probability of low disease activity or remission under treatment with baricitinib.

Disclosure of Interests: Sara Bayat Speakers bureau: Novartis, Koray Tascilar: None declared, Veronica Kaufmann: None declared, Arnd Kleyer Consultant of: Lilly, Gilead, Novartis,Abbvie, Speakers bureau: Novartis, Lilly, David Simon Grant/ research support from: Else Kröner-Memorial Scholarship, Novartis, Consultant of: Novartis, Lilly, Johannes Knitza Grant/research support from: Research Grant: Novartis, Fabian Hartmann: None declared, Susanne Adam: None declared, Axel Hueber Grant/research support from: Novartis, Lilly, Pfizer, EIT Health, EU-IMI, DFG, Universität Erlangen (EFI), Consultant of: Abbvie, BMS, Celgene, Gilead, GSK, Lilly, Novartis, Speakers bureau: GSK, Lilly, Novartis, Georg Schett Speakers bureau: AbbVie, BMS, Celgene, Janssen, Eli Lilly, Novartis, Roche and UCB DOI: 10.1136/annrheumdis-2020-eular.5263

\section{AB0331 EFFICACY, RETENTION RATE AND PREDICTORS OF TOFACITINIB EFFICACY AND RETENTION IN RHEUMATOID ARTHRITIS PATIENTS: HUR-BIO REAL- LIFE EXPERIENCE}

E. Bilgin ${ }^{1}$, F. Ceylan², E. C. Bolek ${ }^{1}$, E. Duran ${ }^{1}$, B. Farisoğulları ${ }^{1}$, G. K. Yardımcı ${ }^{1}$, L. Kılıç ${ }^{1}$, A. Akdoğan ${ }^{1}$, O. Karadag ${ }^{1}$, ş. A. Bilgen ${ }^{1}$, S. Kiraz ${ }^{1}$, A. I. Ertenli ${ }^{1}$, U. Kalyoncu ${ }^{1}{ }^{1}$ Hacettepe Üniversitesi Tıp Fakültesi, Internal Medicine, Rheumatology, Ankara, Turkey; ${ }^{2}$ Hacettepe Üniversitesi Tıp Fakültesi, Internal Medicine, Ankara, Turkey

Background: Tofacitinib (TOF) is an oral Janus Kinase (JAK) inhibitor and is indicated in the treatment of rheumatoid arthritis (RA). Several interventional or observational studies demonstrated its safety and efficacy, however, its real-life retention rate and related factors need to be elucidated further and its efficacy needs to be approved in real-life.

Objectives: To assess the real-life efficacy, retention rate and related factors of both parameter in rheumatoid arthritis patients under tofacitinib.

Methods: We analyzed all RA patients registered to HURBIO database who received at least 1 dose of tofacitinib (for drug retention) and who had at least 1 control visit under tofacitinib (for efficacy). Drug retention rates were calculated using the Kaplan-Meier method and predictors of drug retention were determined by Cox proportional hazard model. Patients were grouped as "responder" or "non-responders according" to DAS28 at last control visit: DAS28-CRP $\leq 3.2$ "Responders"; DAS28-CRP>3.2: "Non-responders". Predictors of response (DAS28-CRP $\leq 3.2$ at last visit) were determined by logistic regression analysis. Reasons for switching and discontinuation were also determined.

Results: For drug retention; a total of 247 (210 (85\%) female) patients were recruited. Mean age was $53.1 \pm 12.6$ years. Mean disease duration was $11.3 \pm 8.0$ years. Rheumatoid factor and anti-CCP antibodies were positive in 160/240 (66.7\%) and 135/207 (65.2\%) patients, respectively. Combination with DMARDs was used in $83.3 \%$ of patients. $55.5 \%$ of patients was biologic-naive. Median follow-up while receiving tofacitinib was 10.2 (IQR:4.0-24.2) months. One-year crude retention rate was $64 \%$. Median duration of drug retention was 24.8 months. Predictors of good tofacitinib retention were (in multivariate analysis): living in Ankara (where our center is located) (HR $1.43(0.96-2.14) ; 95 \% \mathrm{Cl}$ ) and $B M l>25$ (HR $1.46(0.97-2.29) ; 95 \% \mathrm{Cl})$

For efficacy; a total of 204 (174 (85.4\%) female) patients were recruited. Mean age was $53.2 \pm 12.5$ years. Mean disease duration was $11.5 \pm 8.1$ years. Rheumatoid factor and anti-CCP antibodies were positive in 135/198 (68.1\%) and 115/171 $(67.2 \%)$ patients, respectively. Detailed demographic and clinical characteristics of participants were given in table 1. Median follow-up while receiving tofacitinib was 11.6 (IQR:5.2-26.2) months. DAS28-CRP levels at baseline and last visit were 4.8 (IQR:3.9-5.4) and 3.3 (IQR:2.5-4.6), respectively $(\mathrm{p}<0.001)$. At last visit, $19.6 \%$ of patients was in low-disease activity (2.6 $\leq$ DAS28-CRP $\leq 3.2), 26.0 \%$ of patients was in remission (DAS28-CRP<2.6) Predictors of good response to tofacitinib were (in multivariate analysis, adjusted for follow-up duration under tofacitinib): biologic-navie (aOR 2.38 (1.30-4.34); 95\% CI) and RF negativity (aOR 2.12 (1.13-3.95); 95\% Cl)

The most common cause of drug discontinuation was primary failure (in 36/108 patients, 33.4\%).

Conclusion: Tofacitinib seems an effective treatment option for rheumatoid arthritis. Relationship between seronegativity and good response to tofacitinib needs to be elucidated. Also, Clinicians should keep in their mind that in addition to patient char acteristics, socioeconomic factors may influence the adherence to the treatment. Disclosure of Interests: Emre Bilgin: None declared, Furkan Ceylan: None declared Ertugrul Cagri Bolek: None declared, Emine Duran: None declared, Bayram Farisoğulları: None declared, Gözde Kübra Yardımcı: None declared, Levent Kılıç: None declared, Ali Akdoğan: None declared, Omer Karadag: None declared, Şule Apras Bilgen: None declared, Sedat Kiraz: None declared, Ali İhsan Ertenli: None declared, Umut Kalyoncu Consultant of: Abbvie, Amgen, Janssen, Lilly, Novartis, UCB DOI: 10.1136/annrheumdis-2020-eular.788

\section{$\mathrm{AB0332}$ \\ IMMUNOSUPPRESSIVE AND IMMONOMODULATING AGENTS IN RHEUMATOID ARTHRITIS: A SYSTEMATIC REVIEW OF CLINICAL TRIALS AND THEIR CURRENT DEVELOPMENT STAGE}

J. Blaess $^{1}$, J. Walther ${ }^{2}$, J. E. Gottenberg ${ }^{1}$, J. Sibilia$^{1}$, L. Arnaud ${ }^{1}$, R. Felten ${ }^{1}$. ${ }^{1}$ Hopitaux Universitaires de Strasbourg, Service de Rhumatologie, Strasbourg, France; ${ }^{2}$ Hôpitaux Universitaires de Strasbourg, Service de pharmaciestérilisation, Strasbourg, France

Background: Rheumatoid arthritis (RA) is the most frequent chronic inflammatory diseases with an incidence of $0.5 \%$ to $1 \%$. Therapeutic arsenal of RA has continuously expanded in recent years with the recent therapeutic progress with the arrival of conventional synthetic disease-modifying anti-rheumatic drugs (csDMARDs), biological (bDMARDs) and targeted synthetic (tsDMARDs), JAK inhibitors. However, there are still some unmet needs for patients who do not achieve remission and who continue to worsen despite treatments. Of note, only approximately $40 \%$ of patients are ACR70 responders, in most randomized controlled trials. For these patients, finding new therapeutic avenues is challenging Objectives: The objective of our study was to analyze the whole pipeline of immunosuppressive and immunomodulating drugs evaluated in RA and describe their mechanisms of action and stage of clinical development.

Methods: We conducted a systematic review of all drug therapies in clinical development in RA in 17 databases of international clinical trials. Inclusion criterion: study from one of the databases using the keywords "Rheumatoid arthritis" (search date: June 1, 2019). Exclusion criteria: non-drug trials, trials not related to RA or duplicates. We also excluded dietary regimen or supplementations, cellular ther apies, NSAIDs, glucorticoids or their derivatives and non-immunosuppressive or non-immunomodulating drugs. For each csDMARD, bDMARD and tsDMARD, we considered the study at the most advanced stage. For bDMARDs, we did not take into account biosimilars.

Results: The research identified 4652 trials, of which 242 for 243 molecules met the inclusion and exclusion criteria. The developed molecules belong to csDMARDs $(n=21)$, bDMARDs $(n=117)$, tsDMARDs $(n=105)$. 